Herzschr Elektrophys 2021 · 32:421

https://doi.org/10.1007/s00399-021-00799-8

Published online: 12 August 2021

(c) Springer Medizin Verlag GmbH, ein Teil von

Springer Nature 2021

\section{Erratum to: Ablation therapy of postural orthostatic tachycardia syndrome, inappropriate sinus tachycardia and primary electrical diseases: new insights in invasive treatment options in severely symptomatic patients}

Cinzia Monaco ${ }^{1}$ - Antonio Sorgente ${ }^{1}$ Robbert Ramak · Gian Battista Chierchia ${ }^{1}$. Mark La Meir ${ }^{2} \cdot$ Carlo de Asmundis $^{1}$

${ }^{1}$ Heart Rhythm Management Centre, Postgraduate Course in Cardiac Electrophysiology and Pacing, Vrije Universiteit Brussel, Universitair Ziekenhuis, Brussels, Belgium

${ }^{2}$ Cardiac Surgery Department, Vrije Universiteit Brussel, Universitair Ziekenhuis Brussel, Brussels, Belgium
Erratum to:

Herzschr Elektrophys 2021

https://doi.org/10.1007/s00399-021-007

78-z

In this article, the Fellow of the Heart Rhythm Society (FHRS) designation of the author Carlo de Asmundis was incorrectly processed in the author group. The original article has been corrected.

\section{Corresponding address}

\section{Carlo de Asmundis, MD, PhD, FHRS}

Heart Rhythm Management Centre, Postgraduate Course in Cardiac Electrophysiology and Pacing, Vrije Universiteit Brussel, Universitair Ziekenhuis

Laarbeeklaan 101, 1090 Brussels, Belgium carlo.deasmundis@uzbrussel.be carlodeasmundis@me.com
The online version of the original article can be found under https://doi.org/10.1007/s00399021-00778-z

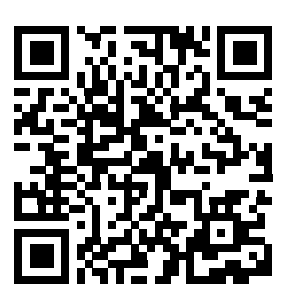

QR-Code scannen \& Beitrag online lesen 